\title{
Strengthening primary health care at district-level in Malawi - determining the coverage, costs and benefits of community- directed interventions
}

Peter Makaula ${ }^{1 *}$ (D, Mathias Funsanani ${ }^{1}$, Kondwani Chidzammbuyo Mamba ${ }^{2,3}$, Janelisa Musaya ${ }^{3}$ and Paul Bloch ${ }^{4}$

\begin{abstract}
Background: Community-Directed Interventions (CDI) is a participatory approach for delivery of essential healthcare services at community level. It is based on the values and principles of Primary Health Care (PHC). The CDI approach has been used to improve the delivery of services in areas that have previously applied Community-Directed Treatment with ivermectin (CDTi). Limited knowledge is available about its added value for strengthening PHC services in areas without experience in CDTi. This study aimed to assess how best to use the CDI approach to strengthen locally identified PHC services at district level.

Methods: This was a comparative intervention study carried out over a period of 12 months and involving four health centres and 16 villages assigned to 1) a conventional Essential Health Package (EHP)/PHC approach at health centre level or 2) an EHP/PHC/CDI approach at community level in addition to EHP/PHC at health centre level. Communities decided which intervention components to be included in the intervention. These were home management of malaria (HMM), long lasting insecticide treated nets (LLIN), vitamin A and treatment against schistosomiasis. The outcomes of the two strategies were compared quantitatively after the intervention was completed with regard to intervention component coverage and costs. Qualitative in-depth interviews with involved health professionals, implementers and beneficiaries were carried out to determine the benefits and challenges of applied intervention components.
\end{abstract}

Results: Implementation of the EHP/PHC/CDI approach at community level as an add-on to EHP/PHC services is feasible and acceptable to health professionals, implementers and beneficiaries. Statistically significant increases were observed in intervention components coverage for LLIN among children under 5 years of age and pregnant women. Increases were also observed for HMM, vitamin A among children under 5 years of age and treatment against schistosomiasis but these increases were not statistically significant. Implementation was more costly in EHP/ PHC/CDI areas than in EHP/PHC areas. Highest costs were accrued at health centre level while transport was the most expensive cost driver. The study identified certain critical factors that need to be considered and adapted to local contexts for successful implementation.

Conclusion: The CDI approach is an effective means to increase accessibility of certain vital services at community level thereby strengthening delivery of EHP/PHC services. The approach can therefore complement regular EHP/PHC efforts.

\footnotetext{
* Correspondence: petmakau@yahoo.co.uk

${ }^{1}$ Research for Health Environment and Development, P.O. Box 345,

Mangochi, Malawi

Full list of author information is available at the end of the article
}

(c) The Author(s). 2019 Open Access This article is distributed under the terms of the Creative Commons Attribution 4.0 International License (http://creativecommons.org/licenses/by/4.0/), which permits unrestricted use, distribution, and reproduction in any medium, provided you give appropriate credit to the original author(s) and the source, provide a link to the Creative Commons license, and indicate if changes were made. The Creative Commons Public Domain Dedication waiver (http://creativecommons.org/publicdomain/zero/1.0/) applies to the data made available in this article, unless otherwise stated. 
(Continued from previous page)

Trial registration: The study was retrospectively registered with the Pan African Clinical Trial Registry TRN: PACTR201 903883154921.

Keywords: Primary health care, Community-directed intervention, Community participation, Essential health service

\section{Background}

Primary Health Care (PHC) is defined as "essential health care made universally accessible to individuals and families in the community through their full participation and at a cost that the community and the country can afford to maintain at every stage of their development in the spirit of self-reliance and self-determination" [1]. PHC was endorsed in 1978 at the Alma Ata, Kazakhstan PHC Conference as a key strategy for attaining equitable access to basic health care, including treatment and prevention of endemic diseases [2]. It is an integral part of health systems in many countries and the first level of contact of individuals, family and community with the public health system. However, as a result of weak health systems PHC implementation remains sub-optimal in Sub-Saharan Africa and access to health services is still a major challenge for a large proportion of the rural population. Weak health systems have also contributed to the persistent high burden of infectious diseases in the rural population [2-5] while hampering effective action against the emerging epidemic of non-communicable diseases. The third goal of the United Nations' Sustainable Development Goals (SDG) advocates for healthy lives and promotion of well-being for all with the Universal Health Coverage (UHC) being central to it [6]. Both the SDG and UHC are inherently broad, but the PHC approach has the potential to deliver essential health services provided that the existing challenges and gaps $[7,8]$ are addressed.

Community participation in health programmes enhances their sustainability and affordability [9-11]. However lack of community involvement in most programmes has led to their failure to achieve the desired results [12]. Community-Directed Intervention (CDI) is defined as a health intervention that is undertaken at the community level under the direction of the community itself [13]. The CDI approach has been used successfully to distribute vitamin A and long lasting insecticide treated nets (LLIN) as well as in home management of malaria (HMM) by CDI implementers [13]. A multi-country study conducted in areas where Community-Directed Treatment with ivermectin (CDTi) had previously been implemented demonstrated that CDI is feasible for integrated delivery of different health services in rural Africa [13]. Recently, the CDI approach has also been implemented successfully in areas without prior experience with CDTi [14-18].
Malawi has no explicit PHC policy but implements PHC services through the Essential Health Package (EHP) programme instituted in 2004 [19]. The present study hypothesize that a further extension of the CDI approach to deliver the EHP/PHC services may help fill gaps related to access and delivery in the EHP/PHC system in a rural Malawian setting. The study builds on findings from formative research that was carried out as part of a multi-country study in 2010 [20] showing that intensified community participation based on the CDI approach may be a realistic means to increase accessibility of certain vital interventions at community level in rural Malawian districts, which had no previous experience with CDTi.

As a basis for the planning and implementation of $\mathrm{EHP} / \mathrm{PHC}$ interventions using the CDI approach in Malawi, the preceding formative research already examined the perceived strengths and weaknesses of existing $\mathrm{EHP} / \mathrm{PHC}$ related strategies and practices, as well as health providers' and consumers' perspectives on $\mathrm{PHC}$ in two rural Malawian districts [20]. The present study was therefore implemented in one of the districts, Mangochi, in collaboration with local and national stakeholders already involved in EHP/PHC efforts within the Ministry of Health in Malawi. Specific objectives were:

1) To determine the effects on intervention components coverage of applying the CDI approach as an add-on to the existing EHP/PHC approach for selected public health services in selected villages in Mangochi District.

2) To assess the costs and benefits of applying the CDI approach as an add-on to the existing EHP/PHC approach in Mangochi District.

3) To identify the perceptions of the involved professionals, CDI implementers and beneficiaries about using the CDI approach including the critical factors for its implementation to strengthen EHP/ PHC services in Mangochi District.

\section{Methods}

\section{Study area and setting}

Malawi is a country in Sub-Saharan Africa with a 2018 population size of $17,563,749$ people and 28 districts organized into three regions: northern, central and southern [21]. The study was carried out in Mangochi, one of the 12 districts in the southern region of Malawi. The 
district is situated on the southern end of Lake Malawi (Fig. 1) and has a total population of 1,148,611 [21]. The district is mainly inhabited by people of Yao and Chewa ethnicities, while Islam (72\%) and Christianity (28\%) are the most practiced religions. Agriculture, fishing and microbusiness enterprising are the main economic activities of people in the district. Adult literacy is $49 \%$, access to safe water supply is $73 \%$, maternal mortality rate is 400 per 100,000 and the infant mortality rate is 169 per 1,000 [22].

\section{Study design}

The study was designed as a controlled implementation study to run for 1 year. The assumption was that the district received what they needed in terms of information, materials, drugs and other supplies to allow them to satisfactorily implement $\mathrm{EHP} / \mathrm{PHC}$ services in rural settings and that the study supported the district processes through a CDI based approach. In total, four health centres and 16 villages were involved in the study. Equal numbers of health centres along with their corresponding villages were randomly assigned to either the intervention or control arm of the study (Table 1).

The support rendered included EHP/PHC/CDI training and supervision of district-based health professionals, health centre-based professionals attached to two health centres and community based volunteers/implementers in eight villages in the intervention arm of the study; no such training and supervision support was provided in the two health centres and eight villages involved in the control arm. For the intervention arm, the EHP/PHC/CDI approach was implemented mainly at community level on top of ongoing regular EHP/PHC activities at health centre levels in the same arm thereby complementing rather than replacing the regular health service delivery. In the control arm, the regular EHP/

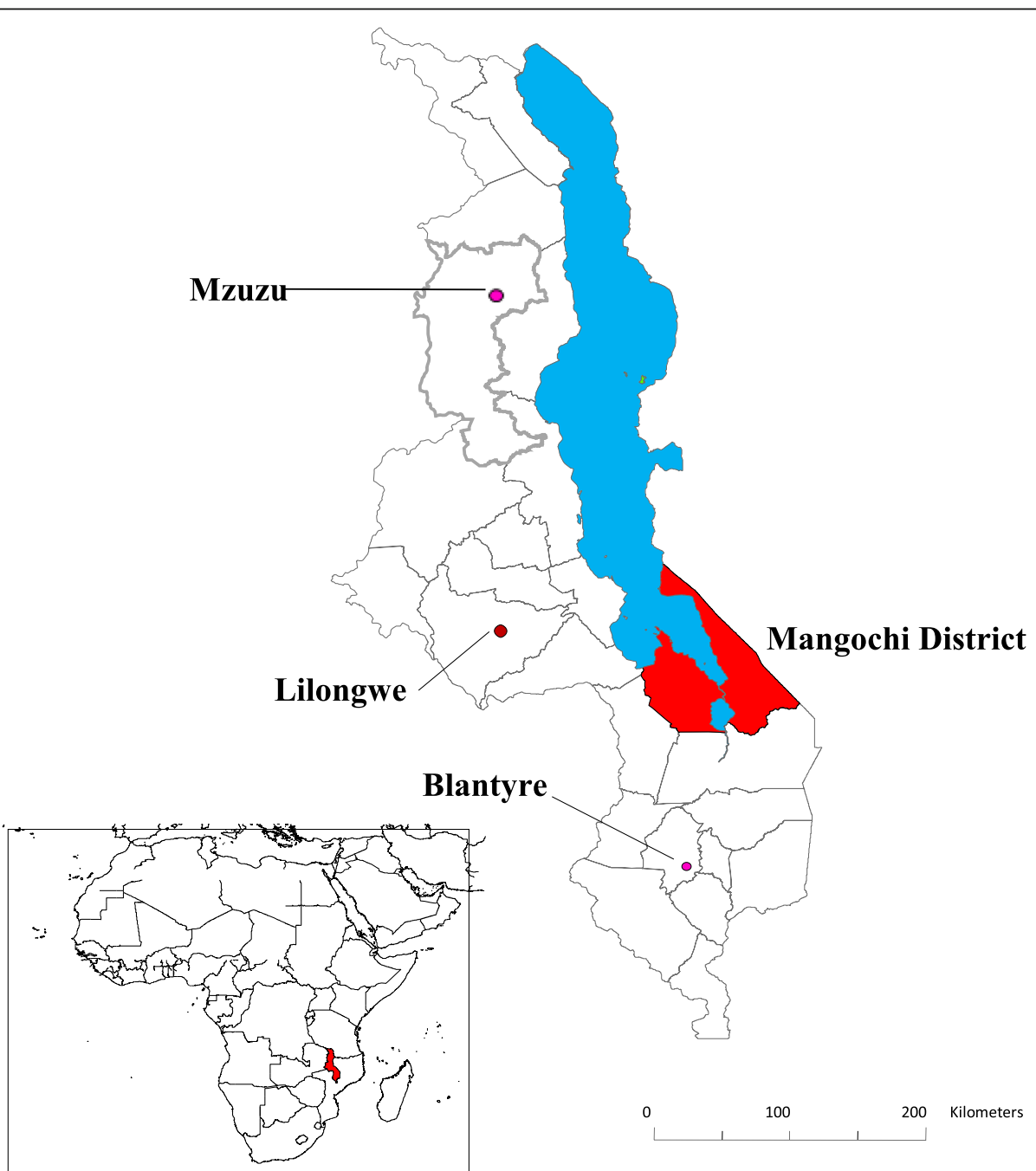

Fig. 1 Map of Malawi showing locations of Mangochi District (in red), Lake Malawi (in blue), major cities of Mzuzu, Lilongwe and Blantyre and the location of Malawi in Africa (red in the inset) (Source: Authors' own map [20]) 
Table 1 List of the involved health centres and villages in Mangochi District according to their assigned study arms

\begin{tabular}{|c|c|c|c|}
\hline District & $\begin{array}{l}\text { Health } \\
\text { centres }\end{array}$ & Villages & Assigned study arm \\
\hline \multirow[t]{4}{*}{ Mangochi } & $\begin{array}{l}1 . \\
\text { Nankumba }\end{array}$ & $\begin{array}{l}\text { 1. Saiti } \\
\text { Tiputipu } \\
\text { 2. } \\
\text { Kamangazula } \\
\text { 3. Kansiya } \\
\text { 4. Binali }\end{array}$ & $\begin{array}{l}\text { A: Intervention - EHP/PHC/CDI } \\
\text { approach }\end{array}$ \\
\hline & 2. Katuli & $\begin{array}{l}\text { 5. Kwitunji } \\
\text { 6. Mponda } \\
\text { 7. Sokole } \\
\text { 8. Kasanga }\end{array}$ & \\
\hline & $\begin{array}{l}\text { 1. } \\
\text { Phirilongwe }\end{array}$ & $\begin{array}{l}\text { 1. Makunula } \\
\text { 2. } \\
\text { Nankamwa } \\
\text { 3. Chimwaza } \\
\text { 4. Mtendere }\end{array}$ & B: Control - EHP/PHC approach \\
\hline & 2. Mase & $\begin{array}{l}\text { 5. Itimu } \\
\text { 6. } \\
\text { Matenganya } \\
\text { 7. Mbalula } \\
\text { 8. Meso }\end{array}$ & \\
\hline
\end{tabular}

PHC system continued to operate at the health centre level without any EHP/PHC/CDI approach being implemented at community level. By applying these approaches, we expected to assess if CDI could strengthen ongoing EHP/PHC efforts in Mangochi District. Both the EHP/PHC and EHP/PHC/CDI strategies were implemented and evaluated over a period of 12 months.

\section{Selection of intervention components}

The research team identified an intervention package that was agreed with the communities and health care providers during the formative phase based on their priority health issues in the setting [20]. To be properly guided on existing policies regarding the implementation of the EHP/PHC/CDI approach at community level the final choice of intervention components also depended on consultations with key health personnel and other professional stakeholders. The following intervention components were finally included in the study: (i) home management of malaria (HMM) and fever to children under 5 years of age, (ii) distribution of long lasting insecticide treated nets (LLIN) to children under 5 years of age and pregnant women, (iii) vitamin A distribution to children under 5 years of age and (iv) treatment of urinary schistosomiasis using Praziquantel (PZQ) for those above 5 years of age.

\section{The CDI process and implementation}

The study involved a total of five district-based officers consisting of the District Environmental Health Officer, District Community Health Nurse, and three Coordinators for malaria, Neglected Tropical Diseases (NTD) and diarrhoea. These were incorporated into the study as trainers and supervisors after being briefed and trained by the research team on the overall aims of the study, principles and processes of the CDI approach, and on available intervention components of the study. In turn the five district-based officers identified and provided training for two health centre based health workers, who were either a Medical Assistant or a Nurse in charge, and two Senior Health Surveillance Assistants from the two participating health centres under the intervention arm of the study to serve as trainers and later as supervisors for community based CDI implementers. The two health centre based staff in turn engaged their respective villages through community meetings from where 32 community based volunteers (one volunteer per each of the four intervention components in each of the eight intervention villages) were identified, trained and assigned roles as CDI implementers of the selected interventions. At every stage at health centre and community levels, both the research and district teams participated in the trainings as observers to ensure adherence to the study protocol. These health centre based staff later continued to supervise and support CDI implementers in their respective villages throughout the implementation period. No briefing and training were offered out to the staff from the corresponding two health centres and eight villages participating in the control arm of the study. Two implementation partner organizations involved in delivery of health services at district level, Icelandic International Aid Agency (ICEIDA) and Amref Health Africa (AHA) were identified and consulted at the beginning of the study.

During the implementation of the CDI process at community level, the health services, implementation partners and the community played the following roles:

1) Roles of district, health centre staff and implementation partners:

- Identified community leadership structures and socio-cultural organizations, and took these into account in all interactions with the community.

- Introduced to the communities the concept of CDI and technical aspects of the interventions.

- Provided and facilitated capacity building, supplies and technical support as required by the interventions.

- Provided and supported supervision based on procedures and criteria of the intervention.

2) Roles of community members:

- Collectively discussed the health problems and possible intervention components from their 
own perspective while considering relevant community knowledge and information provided to them by the health professionals.

- Collectively decided whether they will take responsibility for implementation of intervention at community level.

- Collectively designed the approach to implementing the intervention in their communities and identified the required resources from within their respective communities.

- Collectively planned how, when, where and by whom to implement the interventions.

- Collectively supervised and decided on what support to be provided to CDI implementers and how to monitor the processes.

- Executed the intervention (mainly by CDI implementers).

- Collectively reviewed the implementation process where necessary.

\section{Data collection}

The study employed a mixed-method approach to data collection focusing on quantitative data for coverage and cost estimates during baseline and follow-up, and qualitative data for assessing intervention benefits and evaluating processes. Data were collected at district, health centre and village levels in the intervention and control arms of the study. Research assistants collected the necessary data for the study from the involved health professionals, implementation partners, CDI implementers and beneficiaries using 19 data collection instruments previously used by the research group in a 2008 multi-country study [13]. An additional file shows the instruments that were used during data collection [see Additional file 1]. The instruments consisted of survey questionnaires administered to household heads or representatives at community level for determining intervention coverage, and questionnaires administered to relevant health programme coordinators at district level, incharges at health centres, and leaders at community level, for determining intervention costs. Moreover, Health Management Information System (HMIS) records were reviewed to establish the burden of disease and coverage data at district, health centre and village levels using checklists; Interview guides were used to conduct in-depth interviews with professionals at district and health centre levels, implementation partners at district level and CDI implementers at community level about their perceptions on benefits and critical factors. Finally, focus group discussion guides were used to conduct group interviews with beneficiaries about their perceptions on using the
CDI approach. Using these tools data were collected in both intervention and control areas before (baseline) and after (follow-up) introducing the intervention. All the proceedings of the key informant in-depth interviews and focus group discussions were recorded using digital audio recorders. Table 2 summarizes the methods, purposes, sources and quantities of data collected in the study.

\section{Data management and analysis}

Quantitative data collected through survey questionnaires and checklists were processed and analyzed

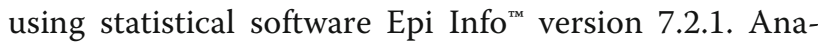
lysis involved calculation of percentages, tabulations and frequencies to estimate coverage of individual intervention components. Furthermore, statistical significance tests using Chi Square were performed on differences in delta values (i.e. differences between baseline and follow-up) for each intervention component between intervention and control groups. The analyses of costs and benefits data were carried out using the following procedures:

- The annual total expenditure on each particular recurrent input (e.g. personnel) was calculated for each intervention component.

- Information on the allocation of shared resources was gathered during the field work by asking the persons in charge to indicate what portion of each individual input (recurrent and capital) was used for intervention components in the year (e.g. proportion of time each staff member spent on each CDI related activity). This information was then used to allocate a percentage of the total costs of each individual (recurrent and capital) input to intervention components.

- The opportunity costs were estimated as the loss of productive labour time due to CDI activities. This implied using the proportion of income a volunteer lost when they were involved in CDI activities. Since CDI activities were mainly implemented in rural areas, data on income was not available and the costing analysis therefore used the minimum wage to ascribe a monetary value to free time devoted by the implementers to CDI activities. Implementers' times were converted and measured in full hours, and this was divided by 8 to give the number equivalent 8 -h working days devoted to CDI activities.

- Cost data were converted to United States Dollars at the existing exchange rate at the time the cost was incurred. Then all the costs were inflated to the prevailing United States Dollars by using the prevailing national Consumer Price Index (CPI). 


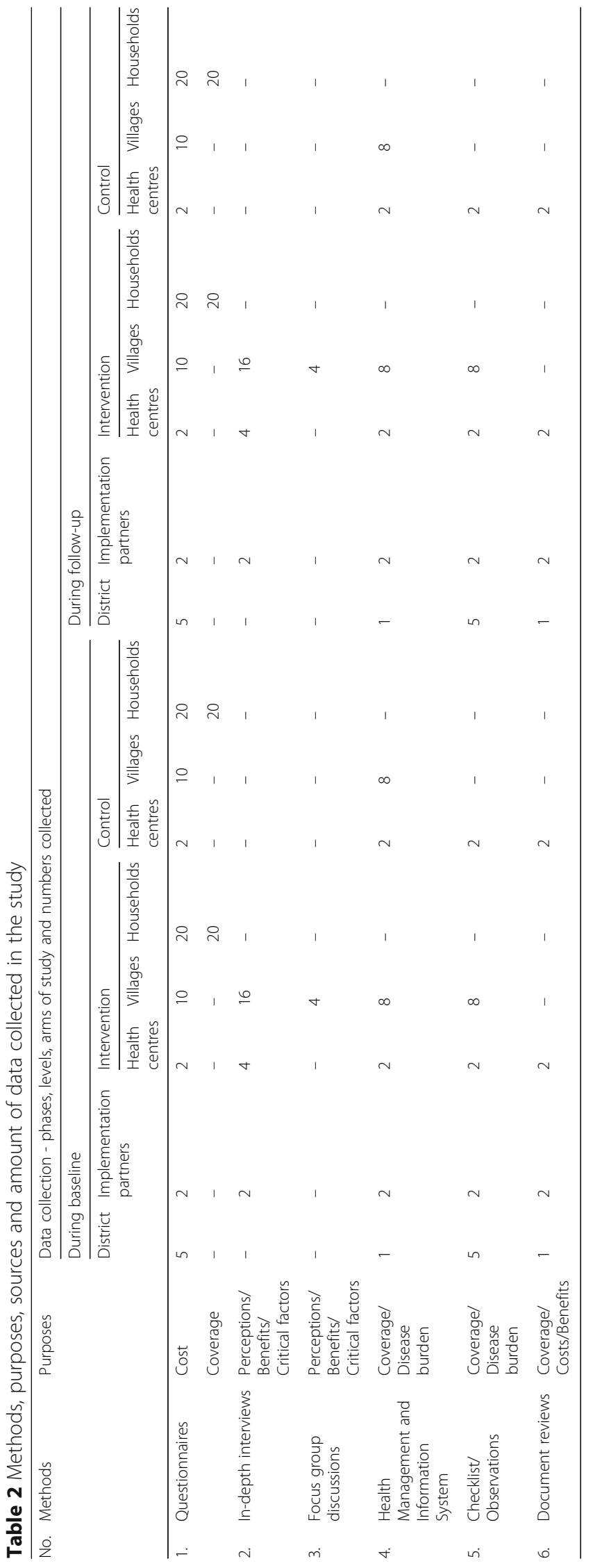


Qualitative data consisted of textual and audio data, including transcripts of key informant in-depth interviews, transcripts of focus group discussions, field notes on observations and other intervention-specific insights, notes and reports from meetings. Transcripts were translated into English and were entered in the computer using standard word processing software. A computer-assisted qualitative content analyses of the data using Atlas-Ti 8, a qualitative data analysis software programme (GmbH 2016) were conducted. Data were analyzed using open coding to come up with cross-classification and retrieval of categories of texts by theme.

\section{Results}

\section{Characteristics of the study areas}

The total population living in the 16 study villages was 20,438 of which $52.4 \%$ were from intervention communities and $47.6 \%$ were from control communities. Of the total of
3,272 children under 5 years of age and 5,615 women of child bearing age living in the study villages, 47.4 and $44.8 \%$ respectively were in the intervention arm of the study. There were 4,511 households in the study villages of which $49.4 \%$ were in the intervention arm of the study. Villages in the intervention arm of the study were more distant from their respective health centres, averaging $12.6 \mathrm{~km}$ (range 2-35), compared to those in the control arm, averaging $4.9 \mathrm{~km}$ (range 2-9). Yao and Islam were the most predominant ethnicity and religion, respectively, in both arms of the study with few exceptions of Chewa and Christian communities in the intervention arm. Table 3 shows the socio-demographic characteristics of the study area.

According to HMIS data only malaria and fever were among the ten leading causes of morbidity between 2012 and 2016 with malaria in the lead followed by acute respiratory infections (ARI) and skin infections (Table 4). Among these diseases, only malaria and fever

Table 3 Socio-demographic characteristics of the study district, involved health centres and communities

\begin{tabular}{|c|c|c|c|c|c|c|c|c|}
\hline \multirow[t]{2}{*}{ Study arm } & \multirow{2}{*}{$\begin{array}{l}\text { Health centre/Nillage } \\
\text { name }\end{array}$} & \multicolumn{3}{|c|}{ Population in crude numbers ${ }^{a}$} & \multirow{2}{*}{$\begin{array}{l}\text { Number of } \\
\text { households }^{\mathrm{a}}\end{array}$} & \multirow{2}{*}{$\begin{array}{l}\text { Approximate } \\
\text { distance to } \\
\text { the health } \\
\text { centre in } \\
\text { kilometers }\end{array}$} & \multicolumn{2}{|c|}{ Prominent } \\
\hline & & Total & $\begin{array}{l}\text { Under } \\
\text { five }\end{array}$ & $\begin{array}{l}\text { Women of child } \\
\text { bearing age }\end{array}$ & & & Tribe & Religion \\
\hline & Mangochi District & $\begin{array}{l}1,099 \\
666\end{array}$ & 179,109 & 242,325 & 199,110 & - & Yao & Islam \\
\hline \multirow[t]{10}{*}{$\begin{array}{l}\text { A. Intervention: EHP/PHC/CDI } \\
\text { approach }\end{array}$} & $\begin{array}{l}\text { 1. Nankumba Health } \\
\text { centre }(22)^{\mathrm{b}}\end{array}$ & 27,349 & 4,649 & 6,290 & 4,791 & - & Chewa & $\begin{array}{l}\text { Christian/ } \\
\text { Islam }\end{array}$ \\
\hline & a) Saiti Tiputipu & 2,346 & 505 & 539 & 414 & 17 & & \\
\hline & b) Kamangazula & 369 & 64 & 75 & 69 & 11 & & \\
\hline & c) Kansiya & 460 & 90 & 106 & 103 & 24 & & \\
\hline & d) Binali & 2,279 & 485 & 592 & 433 & 35 & & \\
\hline & $\begin{array}{l}\text { 2. Katuli Health centre } \\
(37)^{\mathrm{b}}\end{array}$ & 29,280 & 4,978 & 6,734 & 5,390 & - & Yao & Islam \\
\hline & a) Kwitunji & 2,143 & 107 & 491 & 521 & 2 & & \\
\hline & b) Mponda & 811 & 137 & 186 & 198 & 2 & & \\
\hline & c) Sokole & 431 & 69 & 99 & 65 & 5 & & \\
\hline & d) Kasanga & 1,867 & 93 & 429 & 425 & 5 & & \\
\hline \multirow[t]{10}{*}{$\begin{array}{l}\text { B. Control: EHP/PHC } \\
\text { approach }\end{array}$} & $\begin{array}{l}\text { 3. Phirilongwe Health } \\
\text { centre }(20)^{\mathrm{b}}\end{array}$ & 21,859 & 3,716 & 5,028 & 4,878 & - & Yao & Islam \\
\hline & a) Makunula & 2,486 & 508 & 520 & 689 & 7 & & \\
\hline & b) Nankamwa & 386 & 94 & 88 & 66 & 5 & & \\
\hline & c) Chimwaza & 434 & 100 & 100 & 74 & 3 & & \\
\hline & d) Mtendere & 251 & 60 & 60 & 56 & 9 & & \\
\hline & $\begin{array}{l}\text { 4. Mase Health centre } \\
(27)^{\mathrm{b}}\end{array}$ & 31,419 & 5,341 & 7,226 & 6,459 & - & Yao & Islam \\
\hline & a) Itimu & 1,860 & 244 & 893 & 395 & 2 & & \\
\hline & b) Matenganya & 2,761 & 469 & 635 & 586 & 4 & & \\
\hline & c) Mbalula & 690 & 139 & 388 & 199 & 6 & & \\
\hline & d) Meso & 864 & 108 & 414 & 218 & 3 & & \\
\hline
\end{tabular}

${ }^{a}$ Figures represent the entire catchment population sizes for the mentioned district, health centres and villages

${ }^{\mathrm{b}}$ Numbers in brackets represent total villages under each health centre catchment area 
were targeted by the four planned intervention components implemented in the present study.

\section{The effect of CDI on intervention components coverage}

Table 5 presents a summary of the coverage data for each of the four intervention components during baseline and follow-up for both intervention and control arms of the study. The study observed increases in intervention components coverage between baseline and follow-up in all intervention components except distribution of vitamin A among children under 5 years of age in the intervention arm. In the control arm, similar increases in coverage were observed during follow-up in all the intervention components except for HMM and the distribution of vitamin $\mathrm{A}$ in children under 5 years of age. The coverage for LLIN distribution at follow-up increased among children under 5 years of age and pregnant women; increases in coverage were further observed for HMM, vitamin A distribution in children under 5 years of age and treatment of urinary schistosomiasis with Praziquantel among those above 5 years of age. Very high coverage rates (above 70\%) were registered in LLIN distribution and vitamin A distribution among the children under 5 years of age; followed by a mid-level coverage in LLIN distribution among pregnant women; and very low coverage rates for HMM and urinary schistosomiasis treatment both in the intervention and control arms of the study.

Furthermore, when differences (delta values) between baseline and follow-up were calculated for each intervention component in each study arm, it was observed that increases for LLIN among pregnant women and HMM in children under 5 years of age were higher in the intervention arm than in the control arm. For distribution of LLIN and vitamin A in children under 5 years of age, and treatment of urinary schistosomiasis with Praziquantel among individuals above 5 years of age the increases were higher in the control arm than in the intervention arm (Fig. 2).

Chi Square test conducted for each intervention component showed that differences in delta values between intervention and control groups were statistically significant for LLIN distribution in children under 5 years of age ( $p$-value 0.003$)$ and pregnant women ( $p$-value 0.0075 ) but not for the remaining four intervention components.

\section{Assessment of costs, benefits and perceptions of the intervention components}

Cost and benefits analyses of the provision of the four intervention components were conducted based on data collected at three levels of study implementation: district, health centre and community. Cost data collected included seven items on opportunity costs of staff salary, volunteer allowances, training, mobilization, transportation, utilities and supervision (Table 6).

Out of the total amount of resources used to directly implement the selected intervention components at both health centre and community levels most resources were used in the intervention arm of the study. For both arms of the study (intervention and control), the health centre level used more resources than the district level. At community level, only the intervention arm used more resources than the health centre and district levels; the control arm used substantially less resources than the other two levels. According to cost items, transportation costs were the highest across all levels and intervention arms of the study, followed by costs related to supervision and training. For all individual cost items at both health centre and community levels the costs were higher in the intervention arm than the control arm even though a smaller difference in the costs between them was observed at health centre level than at community level.

Table 4 Leading ten causes of morbidity in Mangochi District from year 2012 up to year 2016

\begin{tabular}{|c|c|c|c|c|c|}
\hline \multirow[t]{2}{*}{ No. } & \multirow{2}{*}{$\begin{array}{l}\text { Name of disease/condition causing } \\
\text { morbidity }\end{array}$} & \multicolumn{4}{|c|}{ Total cases treated in the district for years } \\
\hline & & $2012 / 13$ & $2013 / 14$ & $2014 / 15$ & $2015 / 16$ \\
\hline 1. & Malaria 5 years and older & 91,279 & 140,899 & 143,518 & 154,294 \\
\hline 2. & Malaria under 5 years & 106,314 & 156,284 & 163,894 & 162,077 \\
\hline 3. & Acute respiratory infections under 5 years & 56,254 & 65,964 & 76,010 & 73,449 \\
\hline 4. & Skin infection & 22,807 & 30,250 & 33,882 & 28,953 \\
\hline 5. & Diarrhea non-bloody under 5 years & 21,915 & 23,935 & 24,312 & 26,061 \\
\hline 6. & Oral condition & 12,619 & 16,203 & 15,671 & 16,123 \\
\hline 7. & Eye infection & 14,694 & 18,120 & 16,174 & 15,849 \\
\hline 8. & Common injuries and wounds & 14,880 & 14,665 & 14,132 & 14,598 \\
\hline 9. & Dysentery & 8,823 & 8,084 & 11,052 & 7,504 \\
\hline 10. & Sexually transmitted infections (STI) & 8,418 & 8,780 & 9,854 & 10,298 \\
\hline
\end{tabular}

(Source: Mangochi Health and Management Information System, 2016) 


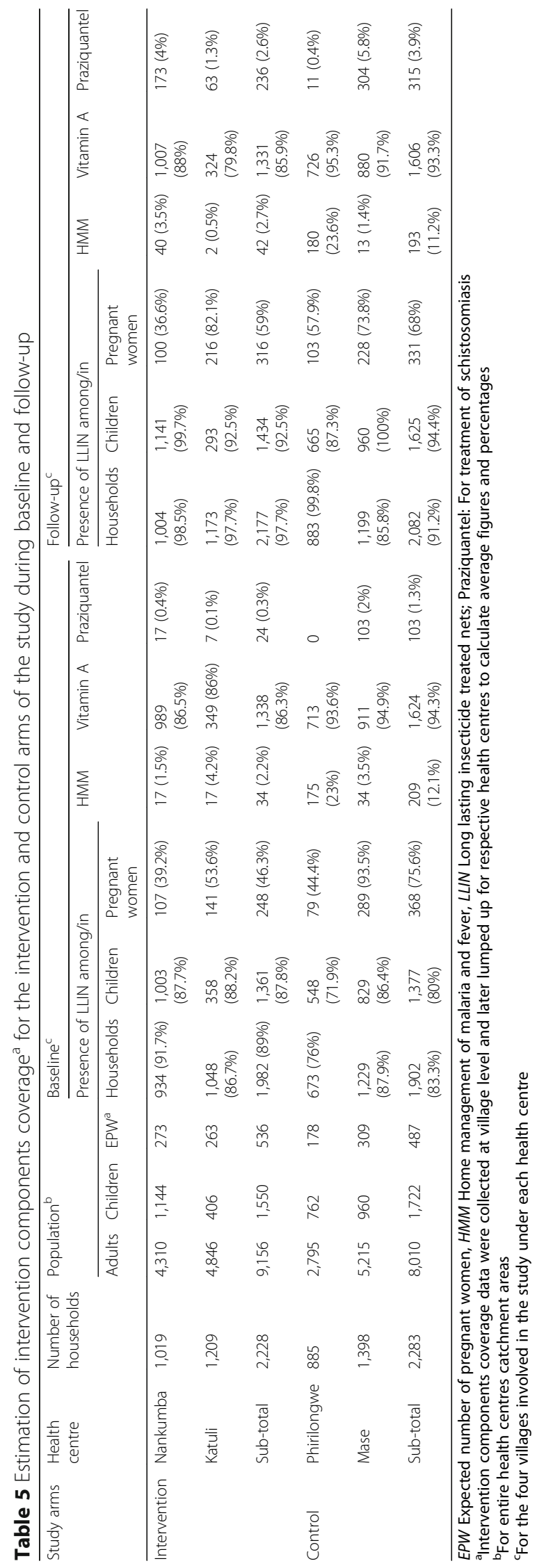




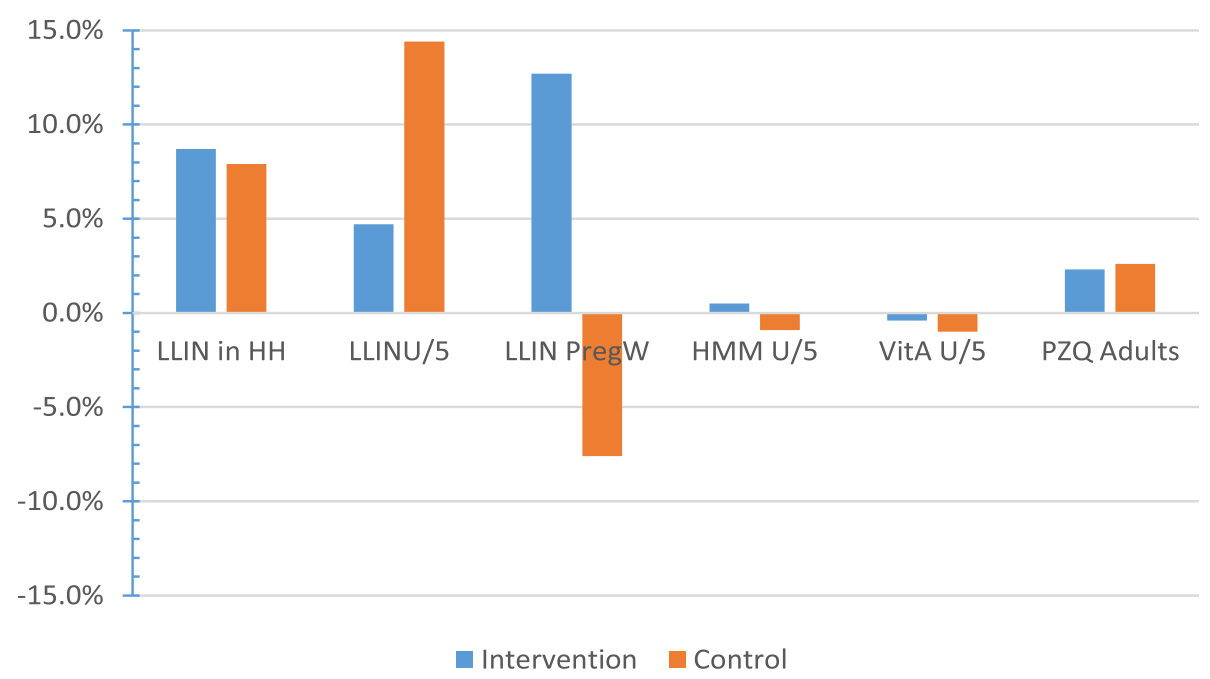

Fig. 2 Difference in average coverage rates for intervention and control villages between baseline and follow-up for specific intervention components in the study

During follow-up, health workers, implementation partners, CDI implementers and beneficiaries expressed satisfaction with the CDI approach. Most intervention components beneficiaries gave ease to access the services as their main reason for being satisfied. The CDI implementers also expressed satisfaction with their new CDI roles. The satisfaction was derived from the benefits accrued from the intervention components, which was mostly expressed in terms of the tangible improvements experienced by individuals in their own and others' health, increased availability and accessibility of amenities such as LLIN and drugs, reductions in absenteeism from school or work due to improved health, timely referrals to health facilities, perceived economic benefits or avoidance of hospitalizations associated with higher uptakes of the intervention components.
On the other hand, the health workers and implementation partners perceived the CDI approach as a mechanism to simplify their task of health service provision by empowering the communities which contributed to the reduction of disease burden from the easily manageable and recurrent illnesses such as malaria and anemia. Health workers also indicated reduced workloads on their part because fewer people were being referred to health centres from CDI communities thereby affording health workers more time for other responsibilities.

\section{Critical factors associated with CDI implementation}

Process data according to the involved professionals further identified a number of key factors that positively impacted on the implementation of the CDI approach. These factors were:

Table 6 Showing a summary of direct costs of implementing intervention components in the study area

\begin{tabular}{|c|c|c|c|c|c|c|}
\hline \multirow[t]{3}{*}{ Cost items } & \multicolumn{5}{|c|}{ Estimated costs according to level and arm used converted to US\$ $\$^{\mathrm{a}}$} & \multirow{3}{*}{$\begin{array}{l}\text { Total US\$ for } \\
\text { cost item (\% } \\
\text { of total) }\end{array}$} \\
\hline & \multirow[t]{2}{*}{ District } & \multicolumn{2}{|l|}{ Health centre } & \multicolumn{2}{|l|}{ Community } & \\
\hline & & Intervention & Control & Intervention & Control & \\
\hline 1. Staff salary & 138.89 & 74.09 & 74.09 & - & - & $287.07(3.9)$ \\
\hline 2. Volunteer allowance & - & - & - & 200.00 & - & $200.00(2.7)$ \\
\hline 3. Training & 270.84 & 145.83 & - & 141.66 & - & $558.33(7.6)$ \\
\hline 4. Mobilization & 104.16 & 83.34 & 83.34 & 83.34 & - & $354.18(4.8)$ \\
\hline 5. Transportation & 625.01 & $1,208.34$ & $1,208.34$ & $1,166.67$ & 388.89 & $4,597.25(62.7)$ \\
\hline 6. Utilities & 41.67 & 31.25 & 31.25 & 20.84 & 6.95 & $131.96(1.8)$ \\
\hline 7. Supervision & 208.34 & 166.67 & 167.67 & 500.00 & 166.67 & $1,209.35(16.5)$ \\
\hline Totals for level/arm (\% of total) & 1,388.91 (18.9) & $1,709.52(23.3)$ & $1,564.69(21.3)$ & $2,112.51(28.8)$ & $562.51(7.7)$ & $7,338.14(100)$ \\
\hline
\end{tabular}

${ }^{\mathrm{a} U S \$}$ United States Dollars 
1) Engaging stakeholders at all levels to make them understand and appreciate the relevance of the CDI as an alternative mode of delivering health services to people in need and if possible to get them fully or partly on board during the CDI implementation process.

2) Maintaining an enabling and conducive environment for applying the CDI approach in terms of securing supportive policies, availability of supplies, and committed health centre staff.

3) Continuing engaging and empowering communities in efforts to promote local participation and ownership of the CDI implementation process.

4) Selecting appropriate volunteers with requisite skills, willing, trusted and motivated to serve as CDI implementers.

\section{Discussion}

Since most health systems in Sub-Saharan Africa are weak and lack mechanisms of delivering essential health services to those who are most in need, community participation increases service delivery and enhance sustainability $[9,13,23,24]$. Since the evolution of CDI from $\mathrm{CDTi}$, there has been a series of studies undertaken to assess its effectiveness in areas with prior experience in onchocerciasis control [13]. Later, CDI has also been tested in areas without prior experience with onchocerciasis control with different modifications and settings [18] such as in the control of schistosomiasis and soil transmitted helminths in rural Western Kenya [14] and Mali [15], in delivering multiple health services in urban poor communities in South-western Nigeria [16], and in delivering health services among Fulani Nomads in Enugu State, Nigeria [17]. All these studies have elicited different findings regarding the feasibility of using CDI to deliver essential health services to people in most need in different settings. This study has added to existing knowledge by testing the applicability of CDI at sub district level of the health system, mainly at health centre and community levels in the rural Malawian health district of Mangochi. It has determined the effectiveness of using the CDI approach to deliver the EHP/ PHC services to strengthen the EHP/PHC system in Mangochi District and assessed the effects of using the approach on coverage, costs and benefits.

Lack of access to essential PHC services and non-involvement of community in their delivery by healthcare systems are often cited as some of the challenges towards attaining universal health coverage $[7-9,13,23]$. The study showed that the CDI approach of delivering health services to those who are most in need is feasible and acceptable to health professionals, partners, CDI implementers and beneficiaries. The findings revealed that in addition to regular EHP/PHC services the CDI approach can be used to deliver some essential health services in rural areas especially where the health system is not able to serve due to either inadequate personnel or geographical barriers. The coverage estimates in this study has shown that the intervention was effective in the distribution of LLIN to children under 5 years of age and pregnant women. However, the intervention was not effective in relation to the distribution of LLIN in households, home management of malaria, vitamin A distribution among under five children and treatment of schistosomiasis among individuals above 5 years of age because the increases observed during follow-up were not statistically significant. For some intervention components statistically significant decreases in coverage were observed at follow-up. This may be attributed to inadequate supplies for the CDI intervention communities e.g. if there were inadequate LLIN or vitamin A supplied to the communities then coverage of LLIN and vitamin A would not improve no matter the levels of community commitment and competences. Similarly, the treatment of schistosomiasis with Praziquantel was preceded by annual district wide mass drug administration campaign and therefore coverage of Praziquantel treatment may have been affected. These examples question the extent to which the community members (as well as district and health centre based staff) were aware of logistical challenges and whether the communities were empowered to deal with them. The study should have ensured that supplies were adequate (e.g. by contributing supplies during the intervention phase). Another possible explanation that affected coverage relates to distance of individual villages from their respective health centres. On average, intervention villages were located $12.6 \mathrm{~km}$ from their respective health centres whereas villages in the control arm were located $4.9 \mathrm{~km}$ away from their respective health centres. An example is Binali, one of the villages under the intervention arm, which is located $35 \mathrm{~km}$ from its health centre. Differences in geographic distances and high costs of healthcare services is often cited as some of the main contributing factors to disparities in access to essential health services across populations in the world $[25,26]$. This disparity in distances between villages and health centres in the two study arms could mean that communities in intervention areas were more disadvantaged in accessing the same intervention components offered in the health centres compared to those in the control areas. One implication of this is that the CDI approach may only be used to complement rather than replace the regular EHP/PHC services offered by the health care system, especially in areas that are located far from health centres. To a 
large extent these findings are in agreement with the findings of similar studies carried out elsewhere [1318 ] and showing that the CDI approach is effective in increasing service coverage and accessibility but is vulnerable to distance and cost factors as shown in this study. When direct costs of implementing CDI were computed into the analysis it revealed that the $\mathrm{EHP} / \mathrm{PHC} / \mathrm{CDI}$ services required almost twice as many financial resources compared to regular EHP/ PHC services. Although this finding was not predictable, the higher costs are mainly due to transport, supervision and training, which are also vital for the success of CDI implementation. This high cost of implementing the CDI approach may be considered a disincentive in short term but as an investment, it may become cheaper in the long term due to the cumulative effect of disability-adjusted life years gained through resultant improved health services or due to the building up of community capacity to handle their own health challenges. The higher costs are also a consequence of a greater number of participants involved in the intervention arm of the study. The inclusion of high coverage intervention components may thus justify the high cost observed due to the implementation of the CDI approach.

The costs of indirect leveraged contributions related to administrative, logistical, personnel, supplies, drugs, LLIN, infrastructure and technical expertise made by participating institutions (i.e. Ministry of Health, University of Malawi College of Medicine, Research for Health Environment and Development and Steno Diabetes Center Copenhagen) towards implementation of the project have not been included in this analysis but are estimated to have covered $75 \%$ of the overall costs of the project. If these indirect contributions were to be included in the determination of the overall costs then it would not be cost effective to use the CDI approach to strengthen delivery of essential PHC services in the District. However, the low coverage obtained in some of the intervention components coupled with the limited effects observed for some of the health services may point to the existence of inherent weaknesses in the selection of intervention components and unforeseeable factors as discussed above. There is therefore a need to re-examine the reasons and factors that may be attributed to the low coverage and limited effects of some of the intervention components as revealed in this study.

For optimum implementation of the CDI approach, the study documented the processes, critical factors, barriers and enablers which can influence either way towards its outcome. It is therefore important when planning similar studies within Malawi or elsewhere, to adhere to the implementation processes and take into consideration all the critical factors described in this paper.
The study revealed that beneficiaries, CDI implementers and health workers were satisfied with the implementation of CDI due to perceived benefits accrued from the implementation of the targeted intervention components. The benefits mentioned associate with easiness to access health services, increased availability of vital amenities, improvements in their health, reduction in absenteeism from school or work, timely referrals to health facilities, avoidance of hospitalizations, reduction of disease burden and reduced workloads in health facilities. These sentiments and perceptions are similar to those also expressed in other studies within the Sub-Sahara African region $[9,13-18]$ and reinforce the need to incorporate the CDI approach to strengthen the delivery of PHC in Sub-Saharan Africa where scarcity of resources in the health sector prevail.

Some barriers that can affect the implementation process were also identified and documented. They include the prevailing shortage of health personnel in district health facilities across Malawi. This intensifies work pressure of available health personnel who find it difficult to manage daily duties, including those related to CDI. Other factors were related to motivation of the involved health staff and volunteers to appreciate the importance of community involvement. These motivational factors were mostly linked to material or monetary expectations due to inadequate remuneration, and provision for food and transport while occupied with CDI related work. Existence of a supportive government policy framework for communitybased delivery of interventions is an enabler for implementation of the CDI approach. To this effect, the Malawi Government is applauded for promulgating two distinct and important policy documents in the National Community Health Strategy and the Health Sector Strategic Plan II, which guarantees commitment and political will from the health systems towards community empowerment through initiatives such as CDI $[27,28]$. Another enabler is the existence of a network of community-based volunteers and health workers who are actively involved in the delivery of various health services at community level in Malawi. This is a valuable resource that can be exploited in favour of the CDI approach.

A major weakness of the study is that it assumed that supplies to the intervention and the control arms were similar and adequate, i.e. if supplies differed then this would affect coverage rates immediately even if all other factors such as well-trained participants, high commitment and engagement, professional delivery of essential health services at community level etc. were adequate. This assumption therefore was not fulfilled since allocation and prioritization of 
resources within the health systems (at district and health centre levels) were beyond the study's control. This has an implication to our interpretation of the study's findings because if the assumption fails then it becomes very difficult to answer if CDI as an add-on to $\mathrm{EHP} / \mathrm{PHC}$ is effective or not. Another weakness in the present study is that despite mainly being implemented in villages with different population sizes, most of our analysis and presentation have lumped the villages together with uniform sample sizes and focused more on the health centres. Embracing the characteristics of individual study villages would have increased the richness of our findings. However, as a minimum the study has made it clear that coverage and cost data were collected in the involved villages even though the data were later lumped together, calculated and presented as health centre averages and percentages.

Important future research areas relate to assessment of resources availability at health centre level and prioritization processes for how and where these resources were used (e.g. at health centre or community level), to test applicability of the CDI approach to improve access to essential health services in exclusively hard to reach rural or peri-urban areas, as Malawi endeavors to attain UHC $[27,28]$ and also to conduct a cost-benefit analysis for using the CDI approach to strengthen PHC delivery at sub-district level in order to inform policy formulation in Malawi or elsewhere.

\section{Conclusions}

This study has demonstrated that implementation of the CDI approach in rural areas of Mangochi District is feasible, acceptable and effective. In terms of intervention components coverage, it was effective for increasing LLIN among children under 5 years of age and pregnant women. It was however not effective for increasing coverage of distribution of vitamin A and home management of malaria among children under 5 years of age and treatment against schistosomiasis in those above 5 years age. Faced with acute shortage of trained health workers in many healthcare systems in low-income countries, the approach can be considered as an add-on for the delivery of selected essential health services in rural areas. It should be used to complement the regular EHP/PHC services offered by the healthcare system especially in areas where personnel and geographical barriers exist. For maximum outcomes, the design and implementation of intervention components have to take into consideration certain critical factors and should be adapted to suit with local conditions and contexts.

\section{Additional file}

Additional file 1: Instruments that were used during data collection for the study consisting of survey questionnaires administered to various respondents, checklists for health facility records, interview guides for key informants and focus group discussion guides with the beneficiaries. (DOCX 99 kb)

\section{Abbreviations}

AHA: Amref Health Africa; ARI: Acute respiratory infections; CDI: Community -directed intervention; CDTi: Community-directed treatment with ivermectin; EHP: Essential health package; EPW: Expected number of pregnant women; GmbH: Gesellschaft mit beschränkter Haftung (Company with limited liability); HMIS: Health Management Information System; HMM: Home management of malaria and fever; ICEIDA: Icelandic International Development Agency; LLIN: Long lasting insecticide treated net; NHSREC: National health sciences research ethics committee; NTD: Neglected tropical diseases; PHC: Primary Health Care; PregW: Pregnant women; PZQ: Praziquantel; SDG: Sustainable Development Goal; UHC: Universal Health Coverage; US\$: United States Dollars; Vit A: Vitamin A

\section{Acknowledgements}

The authors would like to acknowledge the staff at the District Health Office, health centres and implementation partners in Mangochi District for their involvement in this study. The study would not have been possible without the contribution of community members who willingly participated and provided information. The authors are grateful to Dr. Martin OC Ota and Mr. Victor Biza of WHO-Regional Office for Africa, Brazzaville, Congo for their support rendered during the implementation of the study.

\section{Authors' contributions}

PM and PB conceived the project. PM, MF, KCM, JM and PB designed the study, designed the tools, selection and preparation of study areas. PM, MF and KCM trained and supervised data collectors. PM, MF, KCM, JM and PB analyzed and interpreted the data. All authors participated in writing and approved the final manuscript.

\section{Funding}

The study was supported by the WHO-Regional Office for Africa and the Special Programme for Research and Training in Tropical Diseases (TDR) 2016 Small Grants Scheme (REF: AFRO/TDR/SGS/2016.1). These funding organizations did not play any role in the design of the study, collection, analysis and interpretation of data, and in writing the manuscript. The authors of this paper alone are responsible for the views expressed in this publication which do not necessarily represent the decisions or policies of the World Health Organisation.

\section{Availability of data and materials}

The datasets used and/or analyzed during the current study are available from the corresponding author on reasonable request.

\section{Ethics approval and consent to participate}

The study protocol, including the informed consent forms were reviewed and approved by both WHO Ethics Review Committee and Malawi's National Health Sciences Research and Ethics Committee (NHSREC) (Approval \# 628) prior to the commencement of the study. The study was retrospectively registered and approved by the Pan African Clinical Trial Registry: PACTR201903883154921. Community consent was obtained during the very first step in the CDI process when the proposed interventions were discussed with the whole community, and the community collectively agreed on the package for intervention. Informed consent was individually obtained from every study participant at the very beginning before proceeding with their involvement after being explained to clearly about the study objectives and aims using local languages of Chichewa and Chiyao used in the study areas. For participants who were literate, a written consent (see Additional file 1) was obtained while for those not literate a verbal informed consent was obtained instead. Similarly for the study participants who were children (under 16 years of age), consent to participate was collected from their parents or guardians on their behalf. All the research 
instruments that were used at community level were also translated to local languages.

\section{Consent for publication}

Not applicable. The manuscript does not contain any individual person's data in any form.

\section{Competing interests}

The authors declare that they have no competing interests.

\section{Author details}

${ }^{1}$ Research for Health Environment and Development, P.O. Box 345, Mangochi, Malawi. '2District Health Office, P.O. Box 42, Mangochi, Malawi. ${ }^{3}$ College of Medicine, University of Malawi, Private Bag 360, Chichiri, Blantyre 3, Malawi. ${ }^{4}$ Steno Diabetes Center Copenhagen, Niels Steensens Vej 6, NSK 1.11, 2820 Gentofte, Denmark.

Received: 16 November 2018 Accepted: 11 July 2019

Published online: 22 July 2019

\section{References}

1. World Health Organization. Primary health care now more than ever. The world health report. Geneva; 2008. www.who.int/whr/2008/en/

2. World Health Organization. The Ouagadougou declaration on primary health care and health systems in Africa: achieving better health for Africa in the new millennium: World Health Organization - regional Office for Africa; 2008. www.who.int/management/OuagadougouDeclarationEN.pdf

3. Jackson SF, Perkins F, Khandor E, Cordwell L, Hamann S, Buasai S. Integrated health promotion strategies: a contribution to tackling current and future health challenges. Health Promot Int. 2006;21(Suppl 1):75-83.

4. Muula AS. Shortage of health workers in the Malawian public health services system: how do parliamentarians perceive the problem? Afr J Health Sci. 2006:13:124-30.

5. Zere E, Moeti M, Kirigia J, Mwase T, Kataika E. Equity in health and healthcare in Malawi: analysis of trends. BMC Public Health. 2007:7:78.

6. UNDP. Sustainable Development Goals (SDGs). 2016. www.undp.org SDGs Booklet WebEn.

7. Mosquera PA, Hernandez J, Vega R, Labonte R, Sanders D, Dahlblom K, Sebastian MS. Challenges of implementing a primary health care strategy in context of a market-oriented health care system: the experience of Bogota, Colombia. Int J Health Plann Manag. 2014;29: e347-67 https://doi.org/10.1002/hpm.2228.

8. Tanyan K. Primary health care challenges in remote medical setting. Prim Health Care. 2016:6(Suppl 2). https://doi.org/10.4172/2167-1079.C.1:002.

9. Kironde S, Kahirimbanyi M. Community participation in primary health care (PHC) programmes: lessons from tuberculosis treatment delivery in South Africa. Afr Health Sci. 2002;2(1):16-23.

10. Gish $\mathrm{O}$. Malaria eradication and the selective approach to health care: some lessons from Ethiopia. Int J Health Serv. 1992;22:179-92.

11. Elling RH. Theory and method for the cross-national study of health systems. Int J Health Serv. 1994;24(2):285-309.

12. Preston $\mathrm{R}$, Waugh $\mathrm{H}$, Larkins S, Taylor J. Community participation in rural primary health care: intervention or approach? Aust J Prim Health. 2010;16:4-16.

13. Special programme for research and training in Tropical Diseases. Community-directed interventions for major health problems in Africa: a multi-country study final report. Geneva: World Health Organization; 2008. www.who.int/tdr/publications/documents/cdi_report_08.pdf

14. Mwinzi PNM, Montgomery SP, Owaga OC, Mwanje M, Muok EM, Ayisi JG, Laserson KF, Muchiri EM, Secor WE, Karanja DM. Integrated communitydirected intervention for schistosomiasis and soil transmitted helminths in Western Kenya - a pilot study. Parasit Vectors. 2012;5:182.

15. Dabo A, Bary B, Kouriba B, Sankaré O, Doumbo O. Factors associated with coverage of Praziquantel for schistosomiasis control in the community direct intervention (CDI) approach in Mali (West Africa). Infect Dis Poverty. 2013;2:11

16. Ajayi IO, Jegede AS, Falade CO, Sommerfeld J. Assessing resources for implementing a community directed intervention (CDI) strategy in delivering multiple health interventions in urban poor communities in southwestern Nigeria: a qualitative study. Infect Dis Poverty. 2013;2:25.

17. Okeibunor JC, Onyeneho NG, Nwaorgu OC, I'Aronu N, Okoye I, Iremeka FU, Sommerfeld J. Prospects of using community directed intervention strategy in delivering health services among Fulani nomads in Enugu state, Nigeria. Int J Equity Health. 2013;12:24.

18. Brieger WR, Sommerfeld JU, Amazigo UV. The potential for community -directed interventions: reaching underserved populations in Africa. Int Q Community Health Educ. 2015;35(4):295-316 https://doi.org/10.1177/02726 $84 \times 15592757$

19. Republic of Malawi. A joint programme of work for a health sector wide approach (SWAp) 2004-2010. Lilongwe: Ministry of Health and Population, Department of Planning; 2004

20. Makaula P, Bloch P, Banda H, Mbera GB, Mangani C, de Sousa A, Nkhono E, Jemu S. Primary health care in rural Malawi - a qualitative assessment exploring the relevance of the community-directed interventions approach. BMC Health Serv Res. 2012;12:328.

21. Republic of Malawi. Population and Housing Census. Preliminary Report. Zomba: National Statistical Office; 2018

22. Malawi Government. Social Economic Profile. Mangochi: Mangochi District Assembly; 2009.

23. Rifkin SB. Examining the links between community participation and health outcomes: a review of the literature. Health Policy Plan. 2014;29(Suppl 2):98-106.

24. Ghebreyesus TA, Alemayehu T, Bosman A, Witten KH, Teklehaimanot A. Community participation in malaria control in Tigray region - Ethiopia. Acta Trop. 1996:61(2):145-56.

25. Levesque J, Harris MF, Russell G. Patient-centred access to health care: conceptualising access at the interface of health systems and populations. Int J Equity Health. 2013;12:18.

26. Gulliford M, Figueroa-Munoz J, Morgan M, Hughes D, Gibson B, Beech R, Hudson M. What does 'access to health care' mean? J Health Serv Res Policy. 2002;7(3):186-8.

27. Republic of Malawi. National Community Health Strategy 2017 - 2022 integrating health services and engaging communities for the next generation. Lilongwe: Ministry of Health and population, Department of Planning; 2017.

28. Republic of Malawi. Health Sector Strategic Plan II 2017 - 2022 Towards universal health coverage. Lilongwe: Ministry of Health and population, Department of Planning; 2017.

\section{Publisher's Note}

Springer Nature remains neutral with regard to jurisdictional claims in published maps and institutional affiliations.

Ready to submit your research? Choose BMC and benefit from:

- fast, convenient online submission

- thorough peer review by experienced researchers in your field

- rapid publication on acceptance

- support for research data, including large and complex data types

- gold Open Access which fosters wider collaboration and increased citations

- maximum visibility for your research: over $100 \mathrm{M}$ website views per year

At BMC, research is always in progress.

Learn more biomedcentral.com/submissions 